\title{
Radiographic Aspects of Multidrug-Resistant Pulmonary Tuberculosis at the CSDT of Lubumbashi University Clinics
}

\author{
Lumbala Mota Marc ${ }^{1,}$, , Ilunga Mpoyi Tabitha ${ }^{2}$, Bapu Sapu Rebecca ${ }^{3}$, Cibaka Kabasele Léon ${ }^{1}$, \\ Tabu Yekoli Léonard ${ }^{3}$, Kyungu Kambale Guy ${ }^{1}$, Ngoie Muleka Serge ${ }^{4}$, Mulumba Kadiebwe David ${ }^{4}$, \\ Lumbumbu Kasereka ${ }^{5}$, Luyeye Mvila Gertrude ${ }^{1}$
}

${ }^{1}$ Medical Imaging Department, University of Lubumbashi, Lubumbashi, Democratic Republic of Congo

${ }^{2}$ School of Public Health Departement, University of Lubumbashi, Lubumbashi, Democratic Republic of Congo

${ }^{3}$ Department of Ophthalmology, University of Lubumbashi, Lubumbashi, Democratic Republic of Congo

${ }^{4}$ Department of Internal Medicine, University of Lubumbashi, Lubumbashi, Democratic Republic of Congo

${ }^{5}$ Medical Imaging Department, Gécamines Sud Hospital, Lubumbashi, Democratic Republic of Congo

\section{Email address:}

marclumbala@gmail.com(L. M. Marc), tabithailunga7@gmail.com (I. M. Tabitha), rebecca.sapu@gmail.com (B. S. Rebecca), drlcibaka@gmail.com (C. K. Léon), leonardyekoli@yahoo.fr (T. Y. Léonard), kambaleguyk@gmail.com (K. K. Guy), sergemuleka@gmail.com (N. M. Serge), kadiebwed@gmail.com (M. K. David), gluyeye.gl@gmail.com (L. M. Gertrude)

${ }^{*}$ Corresponding author

\section{To cite this article:}

Lumbala Mota Marc, Ilunga Mpoyi Tabitha, Bapu Sapu Rebecca, Cibaka Kabasele Léon, Tabu Yekoli Léonard, Kyungu Kambale Guy, Ngoie Muleka Serge, Mulumba Kadiebwe David, Lumbumbu Kasereka, Luyeye Mvila Gertrude. Radiographic Aspects of MultidrugResistant Pulmonary Tuberculosis at the CSDT of Lubumbashi University Clinics. International Journal of Medical Imaging. Vol. 9, No. 3, 2021, pp. 155-158. doi: 10.11648/j.ijmi.20210903.14

Received: August 19, 2021; Accepted: September 2, 2021; Published: September 26, 2021

\begin{abstract}
Multidrug-resistant pulmonary tuberculosis (MDR-TB) is an infectious disease whose early diagnosis and management still cause problems in countries with very limited resources. Knowing the great consequences of this disease in the life of an individual, we estimated to make an epidemiological and radiographic inventory of this devastating entity at the CSDT university clinics of Lubumbashi. Materials and methods: We conducted a descriptive cross-sectional study including 63 multidrug-resistant tuberculosis subjects aged between 15 and 83 years old at the diagnostic health center and treatment of the university clinics of Lubumbashi (CSDT) from December 2016 to July 2020. The data were analysed using Epi- info 7 and SPSS v 20 software. Results: The average age was $37.4 \pm 14.0$ years. Male sex was the most dominant with $60.3 \%$; the commune of Kampemba was the most affected (41.7\%). HIV co-infection was very low at $4.8 \%$. 90.5\% of patients had experienced a therapeutic failure and $9.5 \%$ had acknowledged having direct contact with a multi-resistant tuberculosis patient. Chest radiographic lesions were dominated by reticular infiltrations (66.7\%) and fibrosis lesions (60.3\%). Conclusion: In view of the results demonstrating that the radiographic pulmonary lesions were dominated by reticular infiltrations and pulmonary fibrosis lesions, the discussion with the other authors highlights the late nature of the diagnosis of multidrug-resistant tuberculosis in Lubumbashi, thus exposing our population to irreversible and disabling pulmonary pathologies.
\end{abstract}

Keywords: Multidrug-resistant, Pulmonary, Tuberculosis, Radiology

\section{Introduction}

Tuberculosis is a potentially serious infectious disease of bacterial origin, mainly affecting the lungs, resulting from the pathogenic effects on the organism of Koch's bacillus, which belongs to the genus Mycobacterium. The droplets of flügge emitted by these patients turn into microscopic nuclei (1 to
10 micrometres) that remain suspended in the air for a long time. These bacilli, once inhaled, will lodge in the pulmonary alveoli and create the initial lesion. It is the leading cause of death from a single infectious agent $[1,2]$.

Multidrug-resistant tuberculosis (MDR-TB) is a form of tuberculosis caused by Mycobacterium that does not respond to isoniazid and rifampicin, the two most potent first line 
anti-tuberculosis drugs $[3,4,11]$. Its treatment is difficult and costly due to the poor response to conventional treatment with first-line drugs [5]. The cure rate is low (between 50 and $70 \%)[3,6]$. Several means are used in the diagnosis including genetic testing (genexpert) supported by physical and microbiological examinations [7].

Another diagnostic tool is the chest X-ray, which is an important tool in the triage and screening of pulmonary TB. It is a useful diagnostic aid when pulmonary TB cannot be confirmed bacteriologically $[8,9]$. It also allows us to indicate the location, area and morphology of the lesion such as cavity, consolidation, pleural effusions and fibrosis [7, 9, 10].

In 2018, approximately half a million new cases of rifampicin-resistant tuberculosis (of which 78\% were multidrug-resistant) were recorded worldwide. Each year, nearly 440,000 people develop MDR-TB and 150,000 people die from this form of the disease $[3,6]$.

The three countries with the largest share of the global burden were India (27\%), China (14\%) and the Russian Federation (9\%). Globally, $3.4 \%$ of new TB cases and $18 \%$ of previously treated cases had multidrug-resistant TB or rifampicin-resistant TB (MDR-TB), with the highest proportions ( $>50 \%$ in previously treated cases) occurring in the former Soviet countries $[2,9,12,6]$.

WHO estimates that between 36,000 and 44,000 cases of multidrug resistance (MDR-TB) occurred in the African region in 2016 [3]. Several factors such as the burden of human immunodeficiency virus (HIV) infection, low socioeconomic status and limited diagnostic and treatment facilities strongly exacerbate the effect of MDR-TB in the developing world $[5,13]$.

The DR Congo reports more than 100,000 cases of susceptible TB each year [14]; it remains a major health problem in the world. One of the factors standing in the way of the eradication of this pandemic is multi-drug resistant tuberculosis (MDR TB). Drug-resistant TB remains a threat to public health [5]. A study conducted in Kinshasa, DRC, in 1998-1999 showed that the prevalence of MDR TB was $2.2 \%$ among new cases of microscopy-positive pulmonary TB $[3,13]$.

From a radiological point of view, several authors worldwide and in Africa have found a point of convergence by establishing a range of radiological signs found in MDR TB (fibrosis, consolidation, cavity, bulla, emphysema,) [7, 9, $10,12,15-17]$.

However, to date, no study has been conducted in our country regarding the radiological lesions of multidrugresistant tuberculosis patients [13].

It is in this context that we ask ourselves the question, what are the radiological lesions that we encounter in the course of multi-resistant tuberculosis in our environment?

\section{Methods}

Study environment and subject selection:

This is a descriptive cross-sectional study, the data for which was collected from the medical records of patients at the tuberculosis diagnostic and treatment centre at the university clinics.

Sixty-three patients were included in the study during the period from December 2016 to July 2020. They were followed by an internist at this institution and referral examinations (inflammatory biology, gene xpert, chest x-ray) were performed.

Inclusion criteria focused on confirmation of pulmonary tuberculosis by sputum zhielnielsen followed by a rifampicin resistance factor on gene xpert and the performance of a chest radiograph.

The chest X-rays, which were of analogue technology, were read by a specialist and a resident in medical imaging at the University Clinics of Lubumbashi.

Data were entered and analysed using Epi-info7.0.2.2 and SPSS v 20 software and ethical considerations were followed in the study.

\section{Results}

Table 1. Age-related characteristics of the patients surveyed.

\begin{tabular}{llll}
\hline $\begin{array}{l}\text { Age group } \\
\text { (year) }\end{array}$ & Workforce & Percentage & $\begin{array}{l}\text { Mean \& Standard } \\
\text { deviation }\end{array}$ \\
\hline $15-23$ & 7 & 17,9 & \\
$24-32$ & 11 & 28,2 & \\
$33-42$ & 6 & 15,4 & \\
$43-51$ & 11 & 28,2 & \\
$52-83$ & 4 & 10,3 & $37.4 \pm 14.0$ years \\
Total & 39 & 100,0 & \\
\hline
\end{tabular}

From this table it can be seen that the average age of the patients surveyed was $37.4 \pm 14.0$ years and the age of the affected patients ranged from 15 to 83 years.

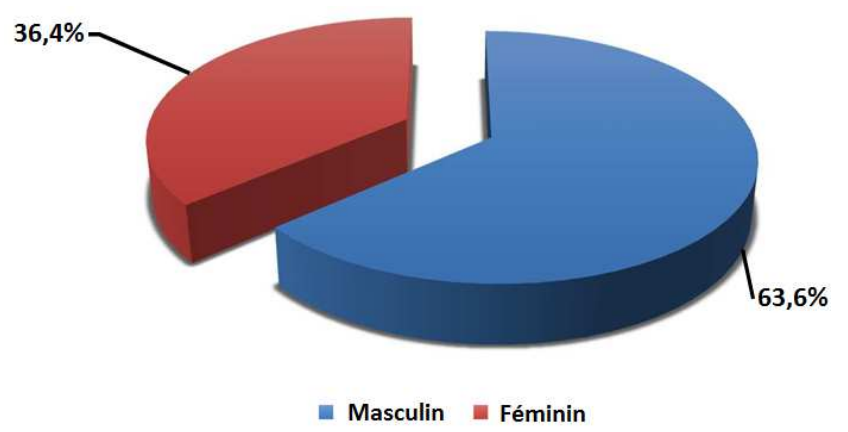

Figure 1. Gender-related characteristics of the patients surveyed.

The figure shows that the male gender was predominant with $63.6 \%$ against $36.4 \%$ female.

Table 2. Characteristic related to the origin of the patients surveyed.

\begin{tabular}{lll}
\hline Municipalities & Workforce & Percentage \\
\hline LUBUMBASHI & 4 & 11,1 \\
KENYA & 1 & 2,8 \\
RUASHI & 1 & 2,8 \\
KATUBA & 2 & 5,6 \\
ANNEX & 13 & 36,1 \\
KAMPEMBA & 15 & 41,7 \\
Total & 36 & 100,0 \\
\hline
\end{tabular}

This table shows that the commune of Kampemba was the 
most represented with $41.7 \%$ of patients followed by the annex commune $(36.1 \%)$ and the rest of the communes were the least represented.

Table 3. Biological and clinical parameters.

\begin{tabular}{lll}
\cline { 1 - 2 } HIV TEST & Workforce & Workforce \\
\cline { 1 - 2 } $\mathbf{n}=\mathbf{3 3}$ & 3 & 9.1 \\
Positive & 30 & 90,9 \\
Negative & $\mathrm{n}=38$ & \\
Treatment failure & 32 & 84,2 \\
Yes & 6 & 15,8 \\
No & $\mathrm{n}=38$ & \\
Multi-resistant contact & 6 & 15,8 \\
Yes & 32 & 84,2 \\
No & & \\
\hline
\end{tabular}

The table states that $9.1 \%$ of the patients surveyed were HIV positive; $84.2 \%$ had experienced treatment failure and $84.2 \%$ were not in contact with multi-drug resistant patients.

Table 4. Characteristic of lung injury in the surveyed patients.

\begin{tabular}{lll}
\hline HIV TEST & Workforce & Workforce \\
\hline Excavation & 21 & 34,4 \\
Reticular infiltration & 42 & 66,7 \\
Nodule & 24 & 38,1 \\
Micronodule & 5 & 8,1 \\
Alveolar Syndrome & 20 & 32,3 \\
Fibrosis & 38 & 60,3 \\
Association & 11 & 19,6 \\
\hline
\end{tabular}

This table shows that pulmonary infiltration was the most represented lung lesion with $66.7 \%$ followed by fibrosis $(60.3 \%)$ and the rest of the lung lesions included were the least represented.

\section{Discussion}

According to our survey, the age groups between 24-32 years and 43-51 years were the most represented, i.e. $28.2 \%$; the average age was $37.4 \pm 14.0$ years. These results are similar to those of Ouédraogo SM in Bobo Dioulasso: 25-34 years; average age was $34 \pm 11.67$ years [16] and Adambounou in Togo: 34.24 years. [18]

However, our results show that the male gender was the most dominant with $60.3 \%$, which is supported by Adambounou [18] and Ouédraogo [16]. Our survey showed that the commune of Kampemba was the most affected $(41.7 \%)$. This can be explained by the proximity of the centre for the management of multi-resistant TB. HIV co-infection was very low at $4.8 \%$. Results supported by the studies of Ouédraogo SM (7.7\%) [16]. Okemba-okimbi found a higher rate than ours (15.4\%) due to a much higher sample size. [17]

In our study, $90.5 \%$ of patients had experienced treatment failure and $9.5 \%$ had acknowledged direct contact with a multi-drug resistant patient. Adambounou in Togo had similar results with $90.2 \%$ of patients being re-treated and $9.7 \%$ of new cases. [18]

Concerning the pulmonary radiographic lesions, they were dominated by reticular infiltrations $(66.7 \%)$ and fibrosis lesions $(60.3 \%)$, which is in contrast to the results of Okemba in Brazza [17] and Ouédraogo in Bobo Dioulasso [16] who demonstrated that caverns were the most represented, respectively $84.6 \%$ and $62 \%$, thus revealing the late nature of the diagnosis of drug-resistant tuberculosis in our environment.

\section{Conclusion}

In view of the results of the radiographic lesions, considering that the pulmonary fibrosis found among the dominant lesions is irreversible and disabling, our concern is based on the fact that the diagnosis of multi-resistant tuberculosis is made late in our environment. This will inevitably lead to repeated bronchial infections, cardiac repercussions (chronic pulmonary heart) and cataclysmic haemoptysis due to ruptures of the bronchial arteries (fatal).

We will suggest to the competent authorities a response plan based on 2 levels:

Combating multidrug resistance:

Increase the number of CSDTs in the city to bring them closer to TB patients;

Motivate destitute TB patients to continue their treatment by providing them with a daily ration;

Ensure that pharmaceutical products are not out of stock in these CSDTs; - Diagnosis and early management of MDRTB:

Providing each structure (CSDT) with equipment for the early diagnosis of multidrug-resistant tuberculosis (expert gene);

Adopting a health policy of routine expert gene testing of all suspected pulmonary TB patients;

Support research to curb this disabling and deadly entity in our community.

Protection of human and animal rights: The authors declare that this study did not involve experiments on patients, subjects or animals.

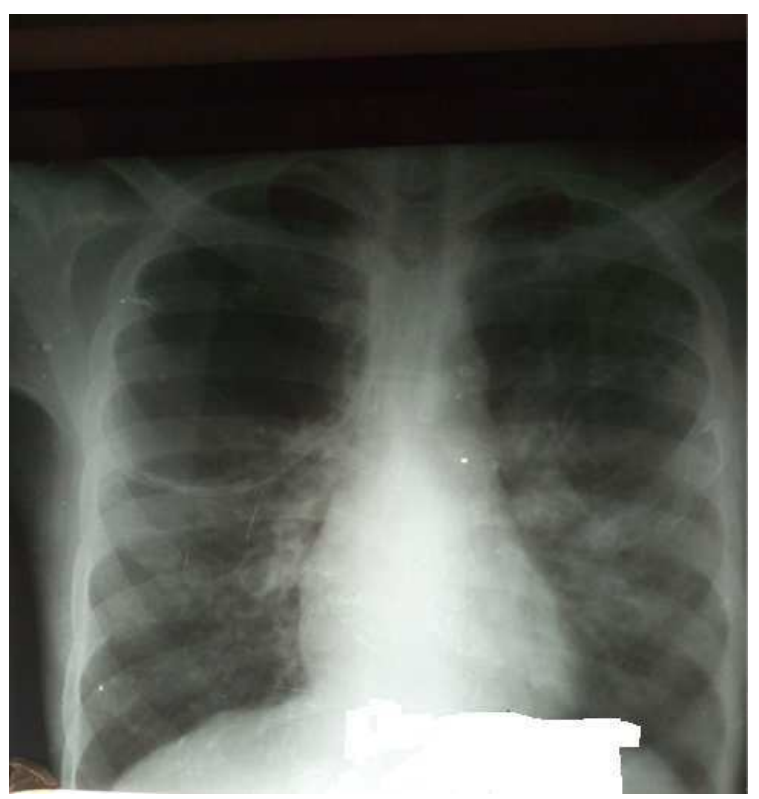

Figure 2. Large emphysematous bubble after MDR-TB. 


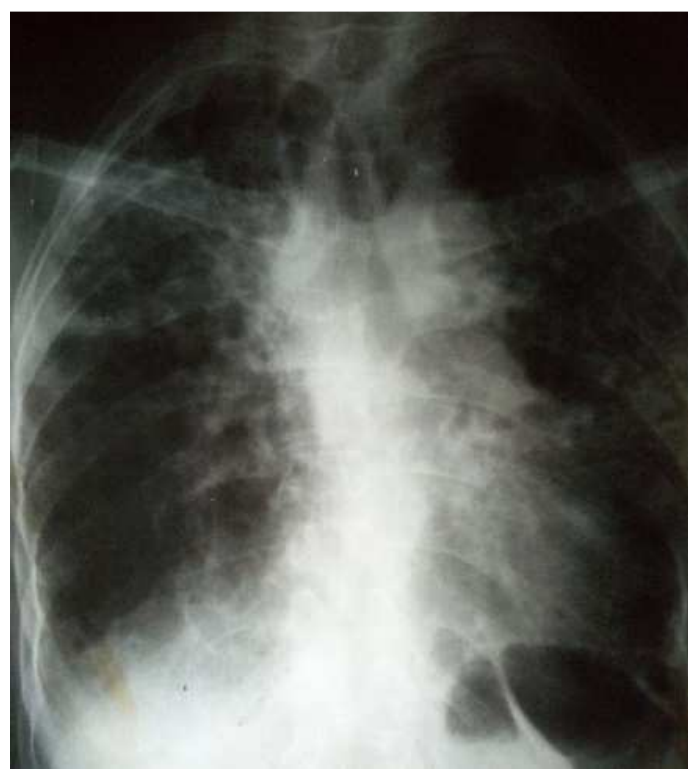

Figure 3. Sequelae of MDR-TB (pulmonary fibrosis).

\section{Confidentiality of Data}

The authors declare that this study does not contain any personal data that could identify the patient or subject.

\section{Contribution and Responsibility of the Authors}

Dr Lumbala Mota Marc: writer, proofreading

Ct Tabitha Ilunga Mpoyi: writer, proofreading

Dr Bapu Sapu Rebecca: Proofreading

Dr Tabu Yekola leonard: proofreading

Dr Cibaka kabasele leon: proofreading

Dr Ngoie Muleka serge: proofreading

Dr Mulumba Kadiebwe David: proofreading

Dr Lumbumbu Kasereka: writer, proofreading

Professor Luyeye Mvila Gertrude: proofreading

\section{Conflicts of Interest}

The authors declare that they have no competing interests.

\section{References}

[1] B. Traoré, "Aspects épidémiologiques, diagnostiques et thérapeutiques de la tuberculose pulmonaire à bacilloscopie négative au service de Pneumo-phtisiologie de 1'," TheseMed. Bamako: FMPOS, pp. 33-34, 2005, [Online]. Available: http://www.keneya.net/fmpos/theses/2005/med/pdf/05M66.pdf.

[2] S. S. Shivekar et al, "Prevalence and factors associated with multidrug-resistant tuberculosis in South India," Sci. Rep., vol. 10, no. 1, pp. 1-11, 2020, doi: 10.1038/s41598-020-74432-y.

[3] A. Misombo-Kalabela et al, "Risk factors for multidrugresistant tuberculosis in the city of Kinshasa in the Democratic Republic of Congo," Pan Afr. Med. J., vol. 23, no. April, 2016, doi: 10.11604/pamj.2016.23.157.6137.
[4] S. Bisuta-fueza et al, "Multidrug-Resistant Tuberculosis in the Democratic Republic of Congo: Analysis of Continuous Surveillance Data from 2007 to 2016," pp. 25-44, 2019, doi: 10.4236/jtr.2019.71004.

[5] K. Mehari et al, "Prevalence and Factors Associated with Multidrug-Resistant Tuberculosis (MDR-TB) among Presumptive MDR-TB Patients in Tigray Region, Northern Ethiopia," vol. 2019, 2019.

[6] C. De, "Démarche du diagnostic microbiologique d ' une tuberculose," 2013.

[7] A. G. Icksan, M. Raja, S. Napitupulu, M. A. Nawas, and F. Nurwidya, "Chest $\mathrm{X}$ - ray Findings Comparison between Multi - drug - resistant Tuberculosis and Drug - sensitive Tuberculosis," no. January, 2018, doi: 10.4103/jnsbm.JNSBM.

[8] L. E. Recueil, End tb. 2018.

[9] E. Young et al, "Radiographic improvement and its predictors in patients with pulmonary tuberculosis," 2009, doi: 10.1016/j.ijid.2009.01.007.

[10] J. B. Riele et al, "International Journal of Infectious Diseases Relationship between chest radiographic characteristics, sputum bacterial load, and treatment outcomes in patients with extensively drug-resistant tuberculosis," Int. J. Infect. Dis., vol. 79, pp. 65-71, 2019, doi: 10.1016/j.ijid.2018.10.026. "Global TB Report 2019 Executive Summary."

[11] Y. X. J. Wáng, M. J. Chung, A. Skrahin, A. Rosenthal, A. Gabrielian, and M. Tartakovsky, "Radiological signs associated with pulmonary multi-drug resistant tuberculosis: an analysis of published evidences," vol. 8, no. 2, pp. 161-173, 2018, doi: 10.21037/qims.2018.03.06.

[12] B. M. Musa, A. L. Adamu, N. A. Galadanci, B. Zubayr, C. N. Odoh, and $\mathrm{M}$.

[13] H. Aliyu, "Trends in prevalence of multi drug resistant tuberculosis in sub-Saharan Africa: A systematic review and meta-analysis," PLoS One, vol. 12, no. 9, pp. 1-15, 2017, doi: 10.1371/journal.pone.0185105.

[14] D. Rdcongo, "the situation of AIDS and tuberculosis in DRCongo.".

[15] J. C. M. Brust et al, "Chest X-Ray Findings in Patients with Multidrug-Resistant Tuberculosis and HIV Co-infection in South Africa," vol. 47, no. 84, p. 84.

[16] B. Emile and O. Act, "Multi-resistant tuberculosis in BoboDioulasso: Epidemiological, clinical, radiographic and evolutionary aspects Multi drug resistance tuberculosis in Bobo-Dioulasso: Epidemiological, clinical, radiographic and evolutionary aspects," 2014.

[17] F. H. Okemba-Okombi, E. Ndinga Essango, M. Kaswa Kayomo, B. O.

[18] Abacka, R. G. Bopaka, and B. A. Ibara, "Multi-resistant tuberculosis in Brazzaville: Epidemiologi-cal, clinical, radiographic and progressive aspects Tuberculose multi résistante à Brazzaville: Aspects épidémiolo-giques, cliniques, radiographiques et évolutifs," doi: 10.12699/jfvpulm.11.33.2020.1. 